\title{
Gene delivery with polycationic fullerene hexakis-adducts $\dagger$
}

\author{
David Sigwalt, ${ }^{a b}$ Michel Holler, ${ }^{a}$ Julien Iehl, ${ }^{a}$ Jean-François Nierengarten, ${ }^{* a}$ Marc Nothisen, ${ }^{b}$ \\ Emmanuelle Morin ${ }^{b}$ and Jean-Serge Remy*b
}

Received 24th December 2010, Accepted 25th January 2011

DOI: $10.1039 / \mathrm{c0cc05783e}$

Polyplexes prepared from DNA and globular compact polycationic derivatives constructed around a fullerene hexakis-adduct core have shown remarkable gene delivery capabilities.

Carbon rich nanostructures have been a major hot topic in chemical research over the past two decades. ${ }^{1}$ In particular, fullerenes combining three-dimensionality with unique electronic properties are extremely promising nanostructures for the preparation of new advanced materials ${ }^{2}$ or biologically active molecules. ${ }^{3}$ Whereas materials science applications of fullerenes have focused an enormous attention, medicinal chemistry of fullerenes has been somehow limited by the absence of solubility of most fullerene derivatives in aqueous media. Nevertheless, fullerenes had a significant impact in the field of biology. $^{3,4}$ In particular, Nakamura and co-workers have shown that cationic fullerene derivatives exhibit a practically useful level of transfection. ${ }^{5,6}$ Importantly, the cytotoxicity of the fullerene derivatives is in general negligible both in the presence and in the absence of ambient light, in spite of the photoreactivity of fullerenes. In a systematic structure-activity relationship investigation performed on a library of 22 fullerene cationic derivatives, Nakamura and co-workers have also shown that an appropriate hydrophobic-hydrophilic balance appears to be essential to form fullerene-DNA nanostructures capable of crossing the cell membrane and thus to release DNA for gene expression. ${ }^{7}$ This study revealed in particular that fullerene hexakis-adduct $\mathbf{C}_{\mathbf{6 0}}\left(\mathbf{N H}_{\mathbf{3}}{ }^{+}\right)_{\mathbf{1 2}}{ }^{8}$ (Fig. 1) is fully inactive as a gene-delivery agent. ${ }^{7}$

The latter observation led to the generally admitted conclusion that compact globular polycations with an isotropic distribution of positive charges are not suitable candidates for transfection studies. ${ }^{9}$ In this communication, we now show that this is

\footnotetext{
${ }^{a}$ Laboratoire de Chimie des Matériaux Moléculaires, Université de Strasbourg et CNRS (UMR 7509),

Ecole Européenne de Chimie, Polymères et Matériaux (ECPM),

25 rue Becquerel, 67087 Strasbourg Cedex 2, France.

E-mail:nierengarten@chimie.u-strasbg.fr

${ }^{b}$ Laboratoire de Chimie Génétique, CAMB, Université de Strasbourg et CNRS (UMR 7199), Faculté de Pharmacie, 74 route du Rhin, B.P. 60024, 67401 Illkirch, France.

E-mail: remy@bioorga.u-strasbg.fr

$\dagger$ Electronic supplementary information (ESI) available: Experimental details for the preparation of the new compounds and representative spectroscopic data; electrophoresis, DLS and TEM analysis of the polyplexes; details for the gene transfer experiments. See DOI: 10.1039/ c0cc05783e
}

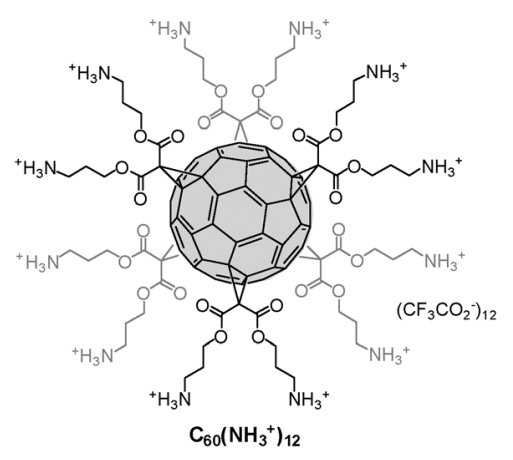

Fig. 1 Compound $\mathrm{C}_{60}\left(\mathrm{NH}_{3}{ }^{+}\right)_{12}{ }^{8}$

indeed not the case. Effectively, polyplexes prepared from DNA and globular compact polycationic derivatives constructed around a fullerene hexakis-adduct core revealed remarkable gene delivery capabilities. As in the case of dendritic vectors for gene delivery, ${ }^{10}$ the efficiency is increased by increasing the generation number of the system. However, in contrast to classical dendritic vectors for which high efficiency requires generally high generation numbers, ${ }^{11}$ the compact hexasubstituted fullerene core led to globular systems even with low-generation dendrons ${ }^{12}$ and thus the gene delivery capability is already optimum for the second generation compound.

The synthesis of the polycationic fullerene hexa-adduct derivatives $\mathbf{G 1 - 3} \mathbf{N H}_{3}{ }^{+}$is depicted in Scheme 1. The hexasubstituted fullerene building block 1 was prepared in two steps according to a reported procedure. ${ }^{13}$ Compounds $\mathbf{G 1 - 3 N _ { 3 }}$ (Fig. 2) were obtained from the corresponding benzylic bromides $\left(\mathrm{NaN}_{3}, \mathrm{DMF}\right)$ which were prepared by following the classical route developed by Hawker and Fréchet ${ }^{14}$ for the synthesis of polybenzylether dendrons (see $\mathrm{ESI} \dagger$ ).

The grafting of azides $\mathbf{G 1 - 3 \mathbf { N } _ { 3 }}$ onto the hexa-substituted fullerene core was achieved under the $\mathrm{Cu}$-catalyzed alkyneazide 1,3-dipolar cycloaddition conditions. ${ }^{13}$ Treatment of 1 with a slight excess of azides $\mathbf{G} \boldsymbol{n} \mathbf{N}_{\mathbf{3}}$ ( $n=1,2$ or 3; 13 equiv.) in the presence of tetrabutylammonium fluoride (TBAF), $\mathrm{CuSO}_{4} \cdot 5 \mathrm{H}_{2} \mathrm{O}$ and sodium ascorbate in $\mathrm{CH}_{2} \mathrm{Cl}_{2} / \mathrm{H}_{2} \mathrm{O}$ gave the corresponding benzyloxycarbonyl (Boc)-protected dendrimers GnNHBoc ( $n=1,2$ or 3 ) in remarkable isolated yields. It is worth noting that the preparation of such fullerodendrimers would be nearly impossible from $\mathrm{C}_{60}$ and the corresponding malonates thus highlighting the advantages of the synthetic strategy 


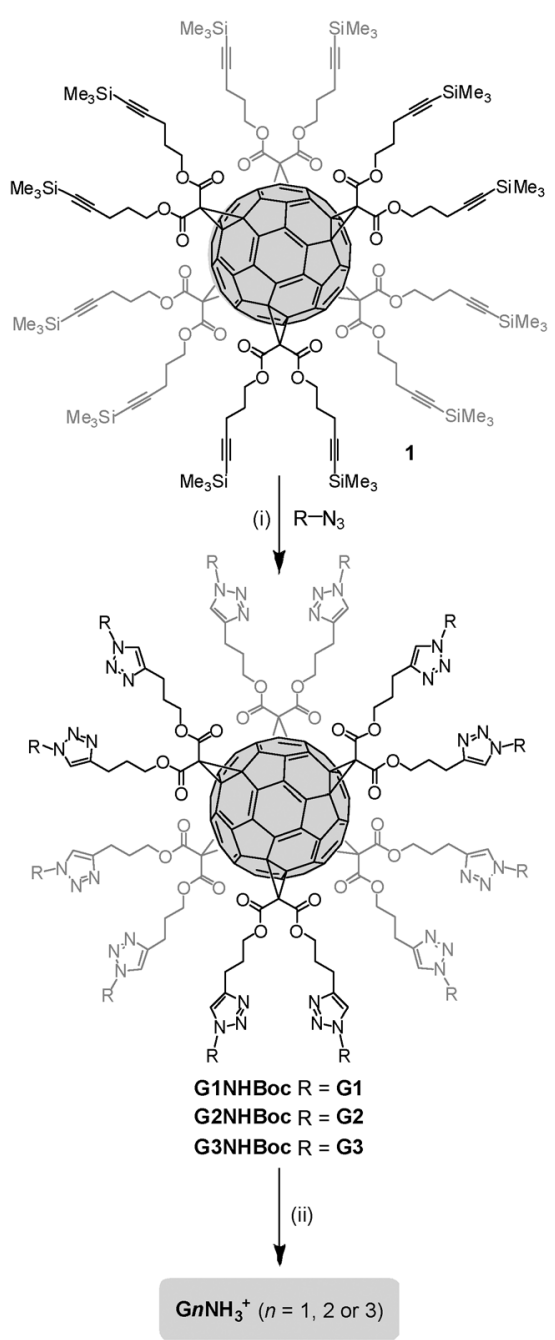

Scheme 1 Reagents and conditions: (i) TBAF, sodium ascorbate, $\mathrm{CuSO}_{4} \cdot 5 \mathrm{H}_{2} \mathrm{O}$ cat., $\mathrm{CH}_{2} \mathrm{Cl}_{2} / \mathrm{H}_{2} \mathrm{O}(1: 1), 25^{\circ} \mathrm{C}$ [from $\mathbf{G 1 N}_{3}$ : G1NHBoc $(85 \%)$; from $\mathbf{G 2 N}_{\mathbf{3}}$ : G2NHBoc (68\%); from $\mathbf{G 3 N}_{\mathbf{3}}$ : G3NHBoc $(89 \%)$ ]; (ii) $\mathrm{CF}_{3} \mathrm{CO}_{2} \mathrm{H}, 25{ }^{\circ} \mathrm{C}$ [from G1NHBoc: $\mathbf{G 1 N H}_{3}{ }^{+}$(quantitative); from G2NHBoc: $\mathbf{G 2 N H}_{3}{ }^{+}$(quantitative); from $\mathbf{G 3 N H B o c : ~} \mathbf{G 3 N H}_{3}{ }^{+}$ (quantitative)].

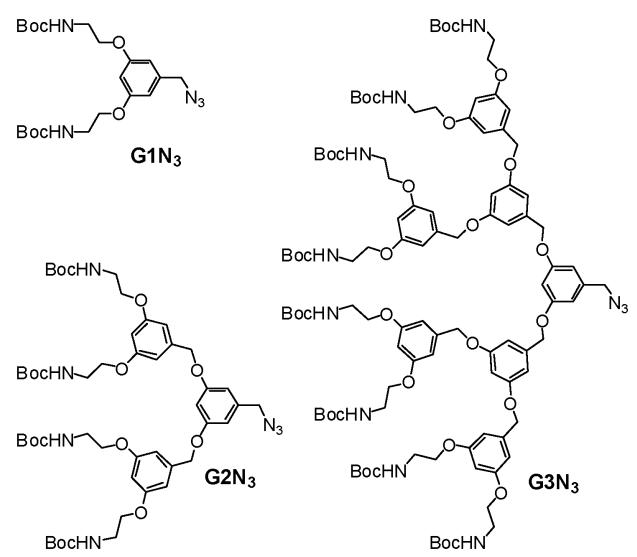

Fig. 2 Azide precursors $\mathbf{G 1 - 3 \mathbf { N } _ { 3 } .}$

based on the post-functionalization of a readily available fullerene hexa-adduct under the $\mathrm{Cu}$-mediated Huisgen reaction conditions. $^{13,15}$
The chemical structure of compounds G1-3NHBoc was confirmed by ${ }^{1} \mathrm{H}$ and ${ }^{13} \mathrm{C}$ NMR, IR and UV/vis spectroscopies as well as by elemental analyses. Their ${ }^{13} \mathrm{C}$ NMR spectra were particularly helpful to evidence their $T_{\mathrm{h}}$-symmetrical structure (Fig. S1, ESI $\dagger$ ). In all the cases, the 3 expected signals of the hexa-substituted fullerene core are clearly observed $(\delta=69.2$ for the $\mathrm{sp}^{3} \mathrm{C}$ atom; $141.1-141.2$ and 145.7-145.9 ppm for the $\mathrm{sp}^{2} \mathrm{C}$ atoms). The high symmetry of G1-3NHBoc was also revealed by the equivalence of the 6 malonate addends. The typical signals of the $\mathrm{sp}^{2} \mathrm{C}$ atoms of the 12 newly formed equivalent 1,2,3-triazole subunits are detected at $\delta$ 121.6-121.8 and 146.7-147.1 ppm. Treatment of G1-3NHBoc with a large excess of trifluoroacetic acid (TFA) gave the corresponding deprotected derivatives $\mathbf{G 1 - 3} \mathbf{N H}_{3}{ }^{+}$as their trifluoroacetate salts in quantitative yields. Inspection of the ${ }^{1} \mathrm{H}$ and ${ }^{13} \mathrm{C} N \mathrm{NM}$ spectra of $\mathbf{G 1 - 3 N _ { 3 }}{ }^{+}$clearly indicates the disappearance of the Boc-protecting groups. Furthermore, the two typical quartets corresponding to the two $\mathrm{C}$ atoms of the trifluoroacetate counteranions are observed in the ${ }^{13} \mathrm{C}$ NMR spectra of $\mathbf{G 1 - 3 N _ { 3 }}{ }^{+}$(Fig. S2, ESI $\dagger$ ). IR data further confirmed the disappearance of the Boc protecting groups ( $c a .3350$ and $\left.1695 \mathrm{~cm}^{-1}\right)$ and the presence of the trifluoroacetate counteranions $\left(1671 \mathrm{~cm}^{-1}\right.$, see Fig. S3-S5, ESI $\left.\dagger\right)$. To further confirm the structure of $\mathbf{G 1 - 3 N _ { 3 }}{ }^{+}$, mass spectra (MALDI-TOF, ESMS and FAB) were recorded under different conditions. However, in all the cases, high level of fragmentation prevented the observation of the expected molecular ion peak as in the case of fullerene hexa-adducts substituted with peripheral sugar residues. ${ }^{16}$

Electrostatic interactions between plasmid DNA and G1-3NH ${ }_{3}{ }^{+}$were quantified by agarose gel electrophoresis (gel shift) of polyplexes ${ }^{17}$ made with increasing N/P (vector amine per DNA phosphate) ratios. Ethidium bromide fluorescence showed full DNA condensation at N/P 2, for all derivatives, both in isotonic $150 \mathrm{mM} \mathrm{NaCl}$ and in iso-osmotic $5 \%$ glucose solutions in water (Fig. S6, ESI $\dagger$ ). Polyplexes were further characterized by Transmission Electron Microscopy (TEM). When prepared in 5\% glucose, polyplexes prepared at N/P 3 and 5 showed spherical 'donut-like' structures, with diameters smaller than $100 \mathrm{~nm}$ (Fig. 3 and Fig. S10, ESI $\dagger$ ). These results were confirmed by Dynamic Light Scattering (DLS) (see ESI $\dagger$ ). Zeta ( $\varsigma$ ) potential measurements made on the same polyplexes showed strongly positive surface charges (Fig. S7-S9, ESI $\dagger$ ). When prepared in $150 \mathrm{mM} \mathrm{NaCl}$, polyplexes become micrometric structures made of aggregated
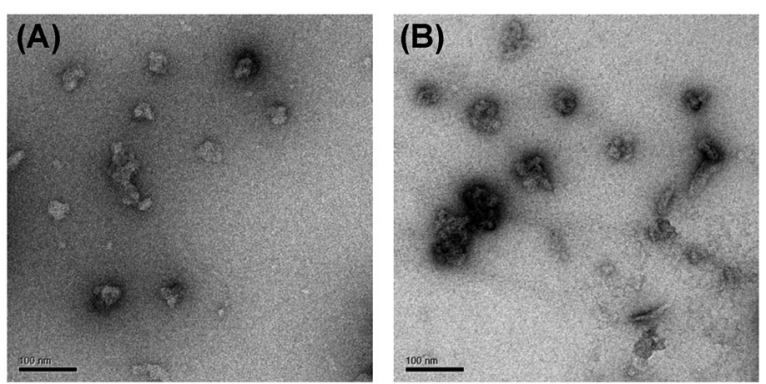

Fig. 3 TEM images of $\mathbf{G}^{2} \mathbf{N H}_{3}{ }^{+} /$pCMVLuc polyplexes at $\mathrm{N} / \mathrm{P} 3$ (A) and $\mathbf{G 3 N H}_{3}{ }^{+} /$pCMVLuc polyplexes at N/P 5 (B) in water with $5 \%$ glucose. The bars indicate $100 \mathrm{~nm}$. 


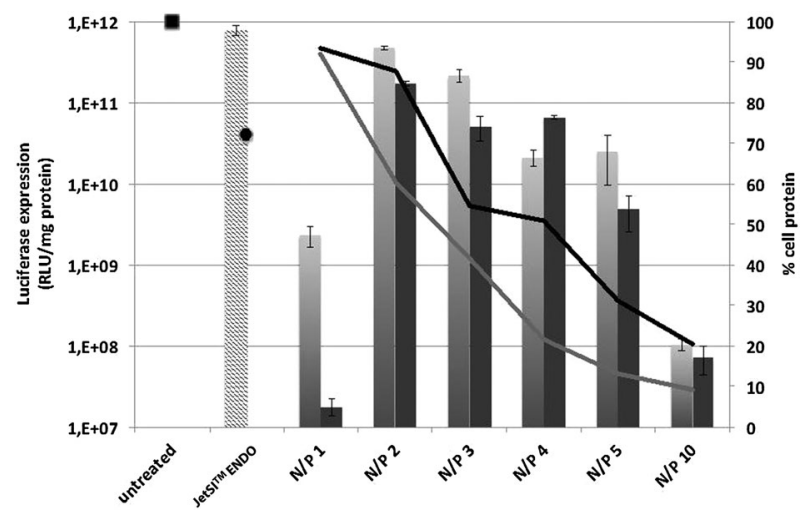

Fig. 4 Gene delivery experiments of pCMVLuc, at various N/P (polyplexes prepared in 5\% glucose solution). Luciferase expression (bars) and percentage of total cellular proteins (lines, square and circle) are given for negative control (untreated), positive control $\left(\mathrm{JetSI}^{\mathrm{TM}}\right.$-ENDO), $\mathbf{G} \mathbf{2} \mathbf{N H}_{\mathbf{3}}{ }^{+}$(light grey), and $\mathbf{G} 3 \mathbf{N H}_{3}{ }^{+}$(dark grey) fullerenes. Means and SD of separate triplicates are given.

spheres (Fig. S13-S15, ESI $\dagger$ ), reminiscent of structures found with polyethylenimine (PEI). ${ }^{18}$ Note that $\varsigma$ potential in the saline conditions could not be determined.

pCMV-Luc gene delivery experiments were conducted with G1-3NH ${ }_{3}{ }^{+}$polyplexes on HeLa cells, prepared either in $5 \%$ glucose (Fig. 4 and Fig. S16, ESI $\dagger$ ) or $150 \mathrm{mM} \mathrm{NaCl}$ (Fig. S17†) solution. In both cases, $\mathbf{G 2 N H}_{3}{ }^{+}$and $\mathbf{G} 3 \mathrm{NH}_{3}{ }^{+}$ had practically the same level of luciferase expression at their optimal N/P ratio (i.e. between $10^{11}$ and $10^{12} \mathrm{RLU} \mathrm{mg}^{-1}$ of protein) than that of a commercially available gene delivery system, namely JetSI ${ }^{\mathrm{TM}}$-ENDO (Polyplus-Transfection), known for its high efficiency/toxicity ratio. Moreover, $\mathbf{G 3 N H}_{3}{ }^{+}$had little if not no toxicity at its optimal N/P 2 ratio. $\mathbf{G 1 N H}_{3}{ }^{+}$had no efficiency when prepared in isotonic solution and only showed a moderate efficiency ( $c a .10^{9} \mathrm{RLU} \mathrm{mg}^{-1}$ of protein, Fig. S16, ESI $\dagger$ ), when prepared in iso-osmotic solution. Strengthened by the fact that electrostatic interactions are lowered in saline conditions, it seems clear that $\mathbf{G 1 N H}_{3}{ }^{+}$only has a limited DNA condensation capacity, due to its low number of protonable amino groups. This is also in good agreement with the results obtained by Nakamura et al. with $\mathbf{C}_{\mathbf{6 0}}\left(\mathbf{N H}_{\mathbf{3}}{ }^{+}\right)_{\mathbf{1 2}} \cdot{ }^{7}$ Conversely, $\mathbf{G} \mathbf{2} \mathbf{N H}_{\mathbf{3}}{ }^{+}$and $\mathbf{G} \mathbf{3} \mathbf{N H}_{\mathbf{3}}{ }^{+}$have enough amino groups to ensure DNA compaction into stable and positively charged polyplexes, that fruitfully deliver DNA into cells. What is more, these spherical polymers exhibit high efficiency, while maintaining low toxicity.

In conclusion, polycationic fullerene hexakis-adducts are efficient and non-toxic gene transfection vectors despite an isotropic distribution of positive charges around a compact globular structure. Owing to the possibility of functionalizing hexasubstituted fullerenes with two or more different functional groups, ${ }^{13,15 d}$ the results reported therein pave the way towards the development of new vectors capable of carrying out several tasks. Work in this direction is underway in our laboratories.

This work was supported by the CNRS (UMR 7509 and 7199). E.M. and D.S. thank the French Ministry of Research (MENRT) for their fellowships. We further thank M. Schmitt for NMR measurements and C. Ruhlmann for TEM experiments.

\section{Notes and references}

1 (a) Fullerenes: Principles and Applications, ed. F. Langa and J.-F. Nierengarten, RSC Nanoscience and Nanotechnology Series, Cambridge, 2007; (b) Carbon Nanotubes and Related Structures: Synthesis, Characterization, Functionalization and Applications, ed. D. M. Guldi and N. Martin, Wiley-VCH, Weinheim, 2010.

2 (a) D. M. Guldi, Chem. Soc. Rev., 2002, 31, 22-36; (b) H. Imahori, J. Phys. Chem. B, 2004, 108, 6130-6143; (c) J.-F. Nierengarten, Sol. Energy Mater. Sol. Cells, 2004, 83, 187-199; (d) J.-F. Nierengarten, New J. Chem., 2004, 28, 1177-1191; (e) J. L. Segura, N. Martin and D. M. Guldi, Chem. Soc. Rev., 2005, 34, 31-47; $(f)$ T. M. Figueira-Duarte, A. Gégout and J.-F. Nierengarten, Chem. Commun., 2007, 109-119.

3 (a) T. Da Ros and M. Prato, Chem. Commun., 1999, 663-669; (b) E. Nakamura and H. Isobe, Acc. Chem. Res., 2003, 36, 807-815; (c) S. Bosi, T. Da Ros, G. Spalluto and M. Prato, Eur. J. Med. Chem., 2003, 38, 913-923.

4 For selected examples, see: (a) S. H. Friedman, D. L. DeCamp, R. P. Sijbesma, G. Srdanov, F. Wudl and G. L. Kenyon, J. Am. Chem. Soc., 1993, 115, 6506-6509; (b) S. H. Friedman, P. S. Ganapathi, Y. Rubin and G. L. Kenyon, J. Med. Chem., 1998, 41, 2424-2429; (c) H. Tokuyama, S. Yamago, E. Nakamura, T. Shiraki and Y. Sugiara, J. Am. Chem. Soc., 1993, 115, 7918-7919; (d) P. Compain, C. Decroocq, J. Iehl, M. Holler, D. Hazelard, T. Mena Barragán, C. Ortiz Mellet and J.-F. Nierengarten, Angew. Chem., Int. Ed., 2010, 49, 5753-5756; (e) M. Durka, K. Buffet, J. Iehl, M. Holler, J.-F. Nierengarten, J. Taganna, J. Bouckaert and S. P. Vincent, Chem. Commun., 2011, 47, 1321-1323.

5 E. Nakamura, H. Isobe, N. Tomita, M. Sawamura, S. Jinno and H. Okayama, Angew. Chem., Int. Ed., 2000, 39, 4254-4257.

6 For other examples, see: (a) C. Klumpp, L. Lacerda, O. Chaloin, T. D. Ros, K. Kostarelos, M. Prato and A. Bianco, Chem. Commun., 2007, 3762-3764; (b) B. Sitharaman, T. Y. Zacharian, A. Saraf, P. Misra, J. Ashcroft, S. Pan, Q. P. Pham, A. G. Mikos, L. J. Wilson and D. A. Engler, Mol. Pharmaceutics, 2008, 5, 567-578; (c) E. Nakamura and H. Isobe, Chem. Rec., 2010, 10, 260-270; (d) R. Maeda-Mamiya, E. Noiri, H. Isobe, W. Nakanishi, K. Okamoto, K. Doi, T. Sugaya, T. Izumi, T. Homma and E. Nakamura, Proc. Natl. Acad. Sci. U. S. A., 2010, 107, 5339-5344.

7 H. Isobe, W. Nakanishi, N. Tomita, S. Jinno, H. Okayama and E. Nakamura, Chem.-Asian J., 2006, 1, 167-175.

8 C. F. Richardson, D. I. Schuster and S. R. Wilson, Org. Lett., 2000, 2, 1011-1014

9 C. Ortiz Mellet, J. M. Benito and J. M. Garcia Fernandez, Chem.-Eur. J., 2010, 16, 6728-6742.

10 M. Guillot-Nieckowski, S. Eisler and F. Diederich, New J. Chem., 2007, 31, 1111-1127 and references therein.

11 J. Haensler and F. C. Szoka Jr, Bioconjugate Chem., 1993, 4, 372-379.

12 (a) X. Camps, H. Schönberger and A. Hirsch, Chem.-Eur. J., 1997, 3, 561-567; (b) A. Hirsch and O. Vostrowsky, Eur. J. Org. Chem., 2001, 829-848.

13 J. Iehl and J. F. Nierengarten, Chem.-Eur. J., 2009, 15, 7306-7309.

14 (a) C. Hawker and J. M. J. Fréchet, J. Chem. Soc., Chem. Commun., 1990, 1010-1013; (b) C. Hawker and J. M. J. Fréchet, J. Am. Chem. Soc., 1990, 112, 7638-7639.

15 (a) J. Iehl, R. Pereira de Freitas, B. Delavaux-Nicot and J.-F. Nierengarten, Chem. Commun., 2008, 2450-2452; (b) P. Pierrat, S. Vanderheiden, T. Muller and S. Bräse, Chem. Commun., 2009, 1748-1750; (c) P. Pierrat, C. Réthoré, T. Muller and S. Bräse, Chem.-Eur. J., 2009, 15, 11458-11460; (d) J. Iehl and J.-F. Nierengarten, Chem. Commun., 2010, 46, 4160-4162.

16 J.-F. Nierengarten, J. Iehl, V. Oerthel, M. Holler, B. M. Illescas, A. Munoz, N. Martin, J. Rojo, M. Sanchez-Navarro, S. Cecioni, S. Vidal, K. Buffet, M. Durka and S. P. Vincent, Chem. Commun., 2010, 46, 3860-3862.

17 P. L. Felgner, Y. Barenholz, J.-P. Behr, S. H. Cheng, P. Cullis, L. Huang, J. A. Jessee, L. Seymour, F. Szoka, A. R. Thierry, E. Wagner and G. Wu, Hum. Gene Ther., 1997, 8, 511-512.

18 D. Goula, J.-S. Remy, P. Erbacher, M. Wasowicz, G. Levi, B. Abdallah and B. A. Demeneix, Gene Ther., 1998, 5, 712-717. 